\title{
Escolarização aberta com RRI para uma participação significativa das comunidades indígenas na educação em rede
}

\author{
Open schooling with RRI for a significant participation of indigenous \\ communities in network education \\ Escolarización abierta con RRI para la participación significativa de las \\ comunidades indígenas en la educación en red
}

LUZIANA QUADROS DA ROSA

Orcid ld: https://orcid.org/0000-0002-5689-4184

Universidade Federal de Santa Catarina

MARCIO VIEIRA DE SOUZA

Orcid Id: http://orcid.org/0000-0002-0165-4036

Universidade Federal de Santa Catarina

ALEXANDRA OKADA

Orcid Id:https://orcid.org/0000-0003-1572-5605

Open University, Reino Unido

\begin{abstract}
Resumo: Este artigo busca problematizar discussões, por meio do pensamento complexo, referentes à abordagem responsible research innovation (RRI) para uma atuação significativa das comunidades indígenas na educação em rede. Esta pesquisa qualitativa inclui as análises bibliográfica e documental, além de observação e realização de entrevistas narrativas com professores indígenas, pesquisadores e gestores públicos. Os referenciais teóricos que tratam de pesquisa e inovação responsáveis e educação em rede contribuem para a análise de significações dos processos da educação escolar indígena. As narrativas apontam para desafios, necessidades e prioridades como categorias identificadas nas deliberações propostas na sexta audiência pública realizada para a construção do I Plano de Educação Escolar Indígena. Por fim, a escolarização aberta surge como uma recomendação para a participação significativa, através dos saberes das comunidades, em projetos de escolarização aberta indígena.
\end{abstract}

Palavras-chave: Pesquisa e inovação responsáveis. RRI. Educação em rede. Escolarização aberta. Educação escolar indígena. 


\begin{abstract}
This article seeks to problematize discussions, through complex thinking, regarding the Responsible Research Innovation (RRI) approach for a significant role of indigenous communities in network education. This qualitative research includes bibliographic and documentary analysis, observation, and the conduct of narrative interviews with indigenous teachers, researchers, and public managers. The theoretical references on Responsible Research and Innovation and Network. Education contribute to the analysis of the meanings of the processes of Indigenous School Education. The narratives make sense of the challenges, needs, and priorities as categories identified in the deliberations proposed at the sixth public hearing beld to build the do I Plano de Educação Escolar Indigena (I PNEEI). Finally, Open Schooling emerges as a recommendation for significant participation, through the knowledge of the communities, in Indigenous Open Schooling projects.
\end{abstract}

Keywords: Responsible research innovation RRI. Network education. Open Schooling. Indigenous school education.

Resumen: Este articulo busca problematizar las discusiones, a través del pensamiento complejo, sobre el enfoque de Responsible Research Innovation (RRI), para una acción significativa de las comunidades indigenas en la educación en red. Esta investigación cualitativa incluye análisis bibliográfico y documental, observación y la realización de entrevistas narrativas con maestros indigenas, investigadores y gerentes públicos. Las referencias teóricas, sobre Investigación e Innovación Responsables y Educación en red, contribuyen al análisis de los significados de los procesos de Educación escolar indigena. Las narraciones dan sentido a los desafios, necesidades y prioridades como categorías identificadas en las deliberaciones propuestas en la sexta audiencia pública celebrada para la construcción del I Plano de Educação Escolar Indigena (I PNEEI). Finalmente, Escolarización Abierta surge como una recomendación para una participación significativa, a través del conocimiento de las comunidades, en proyectos de Escolarización Abierta Indígena.

Palabras clave: Investigación e innovación responsables. RRI. Educación en red. Escolarización abierta. Educación escolar indígena.

\title{
INTRODUÇÃO
}

O processo de avaliação de uma política pública, principalmente, quando se refere a um país como o Brasil - de grandes dimensões geográficas e disparidades sociais -, é complexo e requer o envolvimento de todos os atores sociais. Às vésperas de uma transformação digital global, impulsionada pela crise da pandemia de covid-19, a avaliação de políticas públicas no Brasil precisa considerar de modo mais participativo as necessidades da sociedade brasileira.

Atualmente, para um projeto de lei (PL) ser factual, desde a sua construção e tramitação, implica no atendimento à legislação vigente, a análise de impactos sociais, ambientais e financeiros, conforme orienta o documento "Avaliação de políticas públicas: guia prático de análise ex ante" (IPEA, 2018), elaborado pela Casa Civil da Presidência da República e Instituto de Pesquisa Econômica 
Aplicada (Ipea). Todavia, isso implica na participação social, de modo efetivo, no entendimento do que se propõe, considerando suas consequências, efeitos e resultados.

Ademais, na análise de tais impactos sociais, é relevante a verificação de dados científicos, baseados em pesquisas empíricas de excelência, desde sua coleta até a sua produção. Entretanto, no Brasil, a reflexão sobre as políticas públicas, no âmbito educacional e científico, aponta para um regresso de investimentos e iniciativas.

A título de exemplificação, nos últimos anos, houve cortes de recursos referentes a bolsas de pós-graduação, que foram precedidos por crises econômicas e políticas (CAMARGO JUNIOR; MOURA, 2017); e, especificamente, em junho de 2020, a revogação da Portaria Normativa no 13, de 11 de maio de 2016, pelo Ministério da Educação (MEC), que prevê a implementação de ações afirmativas para negros, indígenas e pessoas com deficiências, nos programas de pósgraduação das instituições federais de ensino, mesmo após a confirmação de sua anulação, trouxe incertezas sobre o futuro dessas ações.

Neste contexto, esses aspectos não só revelam problemas no desenvolvimento de programas de pesquisa das universidades e na formação dos pesquisadores da pós-graduação, bem como traduzem, de modo transversal, as dificuldades dos povos das zonas rurais e das florestas - indígenas, quilombolas e população rural - na busca por políticas de Estado afirmativas e pela garantia de uma educação de qualidade.

Para refletir sobre a educação escolar indígena (EEI) este artigo levanta as seguintes reflexões: sem condições adequadas para estudar em suas comunidades, como esses povos poderão ter um progresso em seus estudos, com uma qualificação profissional, advinda de programas de pesquisa de instituições federais de ensino, ou até mesmo, em nível de pós-graduação? Como as comunidades indígenas podem prosperar harmoniosamente, em respeito à cultura e a sua natureza, em suas comunidades através da educação? Ou, ainda, como essas comunidades podem socialmente participar da construção de políticas públicas, no âmbito educacional, resguardando seus interesses locais?

Nesse sentido, este estudo visa problematizar discussões por meio do pensamento complexo (MORIN, 2006), referentes à pesquisa e inovação responsáveis (RRI) para uma atuação significativa em processos mais participativos das comunidades indígenas na educação. RRI é orginalmente descrita pela Comissão Europeia como responsible research na innovation, sendo uma abordagem que considera a ciência "para" e "com" a sociedade (EUROPEAN COMMISSION, 2015). Espera-se, assim, que a abordagem RRI venha a ser um convite à participação de comunidades indígenas no complexo processo 
de implementação de políticas públicas de maneira inclusiva e sustentável. Este artigo busca contribuir no sentido de avaliar conjuntamente outras dimensões que visam à construção de processos de governança efetivos, a favor de uma EEI de qualidade, considerando, para tanto, as noções elementares descritas no documento norteador utilizado nas audiências públicas para elaboração do I Plano Nacional de Educação Escolar Indígena (I PNEEI), no ano de 2019.

Desse modo, o estudo se baseia nos seguintes princípios: abordagem RRI como uma relevante ação para a implementação de políticas que tratam de pesquisa e inovação (VON SCHOMBERG, 2013) e que dizem respeito ao enfrentamento de irresponsabilidades e de injustiças sociais entre os diferentes atores envolvidos na implementação de produtos e processos que não estão alinhados às necessidades e aos valores da sociedade (FISCHER, 2020; OWEN; PANSERA, 2019); escolarização aberta como elemento essencial na integração da educação formal, não formal e informal (OKADA; RODRIGUES, 2018) para promover habilidades de investigação científica na educação (OKADA; SHERBORNE, 2018); educação em rede na constituição de uma sociedade inclusiva, participativa, democrática e cidadã em rede (CASTELLS, 2010; GOMEZ, 2004; SOUZA, 2015; ROSA et al, 2018).

As comunidades indígenas representam os principais atores interessados na formulação de políticas públicas no campo da EEI. Contudo, se procedimentos legais forem instituídos sem a participação dessas comunidades, qualquer novo processo implementado ou uma tecnologia introduzida (como a construção de uma escola de tijolos e concreto no meio da aldeia) pode impactar de maneira positiva ou negativa a geração com a qual tem contato direto e as futuras. A participação das comunidades indígenas sobre a formulação de políticas públicas de seu interesse é um desafio imprescindível, observado na narrativa de diversos atores presentes nas audiências públicas para a elaboração do I PNEEI.

Assim, os conceitos e as recomendações aqui apresentadas são importantes para: visualizar futuros projetos de escolarização aberta indígena, fundamentados em RRI, e projetar, democraticamente e de maneira responsável, uma participação significativa desses povos na tomada de decisão sobre aspectos sociopolíticos que impactam a sua educação. 


\section{EDUCAÇÃO EM REDE E PESQUISA E INOVAÇÃO RESPONSÁVEIS (RRI)}

Considerando que existem ações governamentais com propostas para a EEI, apresentam-se dois conceitos relevantes que, quando incorporados pela sociedade, podem integralizar propostas mais participativas a favor de uma educação de qualidade neste campo: "educação em rede" e "pesquisa e inovação responsáveis" (RRI).

Educação em rede pode se referir a uma abordagem de cunho nacional, pois se fundamenta na concepção freiriana de educação cidadã e crítica (GOMEZ, 2004), no sentido de uma visão emancipadora, em respeito às pedagogias que orientam os sujeitos a pensar sobre eles próprios, sobre a sociedade em que vivem e sobre a educação que recebem, que almejam receber e que de fato podem construir (GOMEZ, 2015). Ademais, a educação em rede é complexa, pois se reforça no fato da existência de uma sociedade em rede (CASTELLS, 2010).

Nesse sentido, à luz das teorias da sociedade em rede, Souza (2015) considera que a educação em rede se desenvolve no espaço híbrido (físico ou virtual), de maneira ubíqua (em toda parte), e que transforma os papéis dos atores sociais por meio da dinâmica das redes. No cenário apresentado, a internet se torna um poderoso recurso de colaboração, que pode beneficiar a sociedade em geral (SHIRKY, 2008), uma vez que os recursos de informação e conhecimento se integram às redes globais de aprendizagem e conhecimento (AGUILAR, 2012). Na educação, como explica Nunes et al (2017, p. 201), "esta rede tem como base as mídias digitais interativas em sua lógica de trabalho, proporcionando acesso à informação, conhecimento, comunicação e método de aprendizagem."

Todavia, na percepção de Castells (2010), para que ocorra uma mudança social não basta difundir a internet e nem colocar um maior número de computadores nas escolas. Conforme o autor, o que realmente faz sentido à existência da sociedade em rede, numa perspectiva de se saber aproveitar os benefícios da revolução tecnológica, diz respeito às especificidades de cada sociedade, no modo como podem atingir seus objetivos e realizar seus valores. Nesse contexto, não é à toa que a sociedade em rede "exclui a maior parte da humanidade, embora toda a humanidade seja afectada pela sua lógica, e pelas relações de poder que interagem nas redes globais." (CASTELLS, 2010, p. 18).

Assim, a educação em rede, fruto da sociedade em rede e da visão emancipadora, aparece como um conceito de conexão, não só para incluir e conectar as pessoas às redes, mas para determinar o valor da própria rede. Agora, em sequência, apresentam-se os aspectos sobre RRI. 
A abordagem RRI surge na Europa, através do Programa Horizon 2020, realizado pela Comissão Europeia. Deste modo, a RRI visa alinhar desenvolvimento científico e tecnológico e necessidades prioritárias da sociedade local e global. Nesse sentido, todo o projeto RRI deve considerar: educação científica, acesso aberto, engajamento público, governança, igualdade de gênero e ética.

Ademais, através do Projeto Europeu ENGAGE foram definidas 10 habilidades em RRI (Figura 1) que os aprendizes devem desenvolver: elaborar perguntas, interrogar fontes, examinar consequências, estimar riscos, analisar dados, tirar conclusões, criticar afirmações, justificar opiniões, usar a ética e comunicar ideias (OKADA, 2016).

Para Owen (2014) a abordagem RRI reconhece o poder transformador da inovação para criar cenários futuros, considerando sua constituição social e política e sua incorporação de valores. Nesse contexto, a abordagem RRI favorece que os debates sobre pesquisa e inovação sejam realizados pela sociedade, abrindo diálogos sobre como a ciência e a tecnologia podem contribuir para criar um mundo socialmente melhor para as futuras gerações (RRI-TOOLS, 2019).

Alguns aspectos apresentados pela Comissão Europeia, do "Programa de Trabalho 2018-2020: Ciência com e para a sociedade" justificam a participação social, por meio de processos de RRI, tais como: as mudanças em pesquisa e inovação são possibilitadas pelas tecnologias digitais e impulsionadas pela globalização, bem como pela crescente demanda e necessidade de enfrentar os desafios sociais de nossos tempos; o consenso científico parece estar sendo ignorado por alguns formuladores de políticas cujas ações são baseadas em narrativas populistas e não em evidências; a RRI atravessa o Horizonte 2020, envolvendo a sociedade, integrando as dimensões ética e de gênero, garantindo o acesso aos resultados da pesquisa e incentivando a educação científica formal e informal (EUROPEAN COMMISSION, 2015). 


\section{Figura 1 - Habilidades definidas no Projeto Europeu ENGAGE}

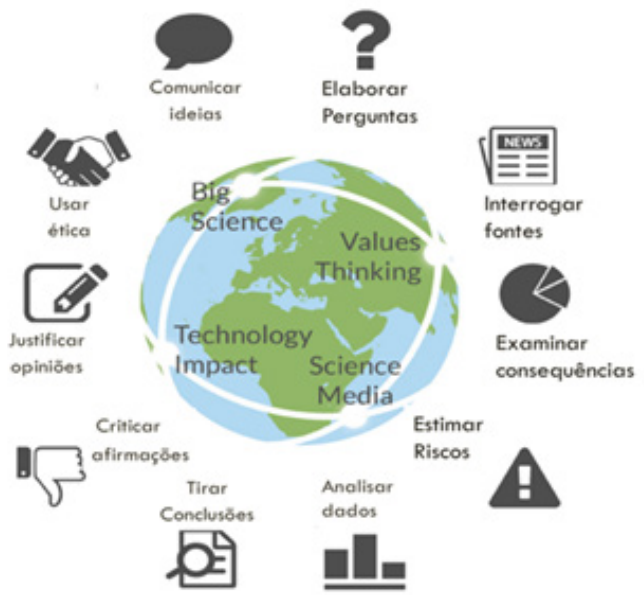

Fonte: https://engagingscience.eu/

A Comissão Europeia identifica, ainda, os desafios enfrentados pela sociedade atualmente, considerando os riscos e os dilemas produzidos muitas vezes pela ciência e tecnologia (RRI-TOOLS, 2019): (a) saúde, mudança demográfica e bem-estar; (b) água, florestas, agricultura e alimentos; (c) energia segura, limpa e eficiente; (d) transporte inteligente, verde e integrado; (e) ação climática, meio ambiente e recursos; (f) a Europa em um mundo em mudança: sociedades inclusivas, inovadoras e reflexivas; (g) sociedades seguras: liberdade e segurança da Europa e dos seus cidadãos. A abordagem RRI busca enfrentar esses desafios alinhando os valores, necessidades e expectativas de todos os atores envolvidos na pesquisa e inovação (RRI-TOOLS, 2019).

O apoio da RRI busca soluções para os desafios apresentados, com base no desenvolvimento da ciência "para" e "com" a sociedade (EUROPEAN COMMISSION, 2015). No Brasil, por exemplo, isso significaria lidar com embasamento científico e participação da sociedade para o enfrentamento dos potenciais aumentos de queimadas do bioma da Amazônia, conforme apontam os registros do Programa de Queimadas do Instituto Nacional de Pesquisas Espaciais (INEP, 2019), ou para a superação da pandemia da covid-19, que vitimou mais de 130 mil pessoas no país, segundo informações da Agência Senado (SENADO FEDERAL, 2020). 


\section{PROCEDIMENTOS METODOLÓGICOS}

Em atendimento ao objetivo proposto, este artigo fundamenta-se em uma abordagem qualitativa, na qual se procura compreender os significados que indivíduos ou grupos atribuem a um problema social (CRESWELL, 2010; MINAYO, 1994). Trata-se de uma pesquisa exploratória, cujos métodos adotados são o levantamento bibliográfico e documental, observação e entrevistas narrativas.

O método qualitativo de pesquisa caracteriza-se por abordar questões relacionadas às singularidades do campo e dos indivíduos pesquisados, sendo as entrevistas narrativas um método potente para uso dos investigadores que dele se apropriam. Elas permitem o aprofundamento das investigações, a combinação de histórias de vida com contextos sócio-históricos, tornando possível a compreensão dos sentidos que produzem mudanças nas crenças e valores que motivam e justificam as ações dos informantes. (MUYLAERT et al, 2014, p. 193).

Nesse contexto, destaca-se que a determinação do design deste estudo teve início, em maio de 2019, quando houve a primeira Audiência Pública para a construção do I PNEEI, em Manaus-AM. Essa audiência foi promovida pelo MEC, através dos esforços da Secretaria de Modalidades Especializadas de Educação (Semesp). Essa audiência pública, assim como as demais que a sucederam, contou com a participação de professores, estudantes, gestores indígenas, organizações indígenas e indigenistas, sistemas de ensino (estadual e municipal), instituições de ensino superior, Comissão Nacional de Educação Escolar Indígena (CNEEI), secretarias e autarquias vinculadas ao MEC, Fundação Nacional do Índio (Funai) e demais órgãos que atuam com a EEI nos respectivos estados da federação (MEC, 2019).

Todavia, o emprego da técnica de coleta de dados ocorre no encontro da sexta audiência pública para construção do I PNEEI, realizada na cidade de Chapecó-SC, em colaboração com a CNEEI. Na ocasião, em outubro de 2019, foram coletadas as informações relevantes através de observação, bem como realizadas entrevistas com atores significativos do processo: dois professores indígenas, um diretor indígena, três gestores públicos do MEC e uma pesquisadora de uma universidade pública.

O referencial teórico é alicerçado nas temáticas RRI e educação em rede, em contextos interdisciplinares, que envolvem abordagens sobre inovação e tecnologias na educação. A técnica documental oferece embasamento de conceitos, conhecimentos e informações sobre grupos e indivíduos, a partir do interesse da pesquisa sobre EEI (CELLARD, 2008; GIL, 2008). A observação auxilia no papel do pesquisador como o de um espectador, em relação ao objeto 
observado (GIL, 2008). As entrevistas narrativas apresentam em profundidade aspectos específicos do contexto situacional em que se encontram os entrevistados, na qual se valorizam os relatos orais que não estão disponíveis em documentos (MUYLAERT et al, 2014).

No tratamento dos dados, determinam-se três categorias - desafios, necessidades e prioridades - para associar e relacionar significados, justificando as ações dos entrevistados (MUYLAERT et al, 2014), nas redes tecidas por eles, para compor os processos da EEI. Desse modo, os procedimentos sistemáticos adotados permitem a construção de teorias que favorecem a compreensão do fenômeno estudado, cujo tratamento dos dados, após ordenação e classificação (com apoio do recurso eletrônico Voyant Tools) contextualiza a análise, propriamente dita, apoiando assim os futuros questionamentos para o desenvolvimento de novas pesquisas (MINAYO, 1994).

\section{EDUCAÇÃO ESCOLAR INDÍGENA}

O parecer CNE/CEB n ${ }^{\circ}$ 13/2012, referente às Diretrizes Curriculares Nacionais para a Educação Escolar Indígena, já contextualiza, no âmbito desta educação que é garantida como um direito constitucional, que ela deve ser desenvolvida de maneira plena e:

[...] precisa estar alicerçada em uma política linguística que assegure o princípio do biliguismo e multilinguismo, e em uma política de territorialidade, ligada à garantia do direito a terra, a auto-sustentabilidade das comunidades e a efetivação de projetos escolares que expressem os projetos societários e visões de mundo e de futuro dos diferentes povos indígenas que vivem no território nacional. (BRASIL, 2012).

Esse parecer leva em conta que as habilidades básicas desenvolvidas na EEI devem considerar a língua dos nativos, a cultura da região e o desenvolvimento sustentável para que os povos não percam sua identidade. Neste contexto, buscando embasar argumentos para uma participação social indígena mais efetiva no tocante à sua educação, vale-se das ideias de Thomaz de Almeida (2001), sobre ser necessário considerar a organização da realidade cultural indígena, em que se deve "resgatar as múltiplas dimensões de uma realidade indígena contemporânea e sua relação com o mundo regional, com o qual ela dialoga e do qual se diferencia marcadamente." (MURA, 2002, p. 215). 
Nesse sentido, desde decisões políticas a projetos comunitários educacionais, cabe separar o que é educação convencional de EEI, importando, sobretudo na possibilidade de uma comunidade decidir sobre sua própria educação, afirmando na sua cultura sobre o que permanece ou se transforma (ABBONIZIO; GHANEM, 2016).

A realização das audiências públicas, com a presença e participação das comunidades indígenas, foi um passo importante a ser dado, prevendo a elaboração do I PNNEI, um documento a ser entregue ao Conselho Nacional de Educação (CNE) para a elaboração de diretrizes nacionais dos parâmetros de qualidade da educação indígena (MEC, 2019). No entanto, observa-se que as comunidades, em geral, não estão preparadas para participar ativamente das discussões de políticas públicas. Em ocasiões como da audiência pública ocorrida no município de Chapecó-SC, há o registro de um número extenso de reclamações e dores, em que poucos são os propósitos de soluções que partem da própria comunidade para resolver as suas necessidades.

Nesse caso, os relatos dos participantes, da audiência pública usaram seu direito de fala para relatar diversas carências vivenciadas em suas aldeias. No Brasil, dados do Censo da Educação Básica (INEP, 2018) apontam o número elevado de escolas indígenas sem tratamento de água (1.970), esgoto sanitário (1.634) nem energia elétrica (1.076), falta de biblioteca (3.077) e banda larga (3.083). Outros pontos observados nos dados do Inep (2018), divulgados pelo MEC (2019), é que cerca de 30\% (1.029) das 3.345 escolas não funcionam em prédios escolares e quase metade (1.546) não utiliza material didático específico da educação indígena. Esses dados evidenciam situações delicadas em relação à educação dos povos indígenas.

Os temas debatidos na sexta audiência pública sobre a elaboração do I PNEEI foram: (I) Gestão da educação escolar indígena e regulamentação das Diretrizes Curriculares Nacionais da Educação Escolar Indígena; (II) Territórios etnoeducacionais; (III) Infraestrutura; (IV) Práticas pedagógicas e material didático; (V) Valorização e formação de professores indígenas; (VI) Oferta da educação escolar indígena e de ensino superior; (VII) Sistema de avaliação da EEI. Para tanto, a Semesp seguiu metodologia configurada pelo Ipea, de modelo lógico de configuração de desenho de programas, para se prospectar o desenho de uma ação governamental, a partir de uma proposição de problemas e identificação de suas causas críticas.

Os problemas destacados, nessa versão preliminar do I PNEEI, são frutos de 25 deliberações propostas na II Conferência Nacional de Educação Escolar Indígena (CONEEI), cujo tema tratava de "Sistema Nacional de Educação e Educação Escolar Indígena: regime de colaboração, participação e 
autonomia dos povos indígenas". O processo em sua totalidade, baseado na metodologia adotada, entre outras condições, previa resultados para fortalecer o regime de colaboração e controle social para a consulta informada aos diversos atores envolvidos.

Os resultados finais esperados, a partir das audiências de elaboração do I PNEEI, buscam como objetivos para a EEI: regulamentação das Diretrizes Nacionais nos conselhos de educação e gestão organizada e participativa; regime de colaboração operando de acordo com o imperativo de consulta e com a territorialidade dos povos indígenas; infraestrutura adequada; práticas pedagógicas e materiais didáticos específicos; valorização e formação específica de professores indígenas; oferta específica e intercultural de educação infantil, ensino médio, educação profissional, EJA e ensino superior para os povos indígenas; sistema de avaliação específico e intercultural.

\section{ANÁLISE DAS ENTREVISTAS COM OS ATORES ENVOLVIDOS}

Nesta pesquisa, utilizou-se o recurso eletrônico Voyant Tools como ferramenta auxiliar para a visualização da frequência dos termos mais usados e de suas possíveis relações; consequentemente, o recurso facilita a análise qualitativa, pois permite identificar as palavras com maior peso de significação nas narrativas dos entrevistados.

Para o diretor da escola indígena, a palavra "gente" teve maior impacto, podendo ter aparecido em função deste entrevistado, especificamente, assumir seus diferentes papéis na audiência (membro da comunidade indígena, estudante, professor, diretor, membro do CNEEI). Ademais, essa palavra evidencia, em meio essa multiplicidade de papéis, o peso da responsabilidade de "conseguir" algo determinante para as comunidades indígenas, tal como ter o nível básico de ensino, para além do nível fundamental, ofertado atualmente em suas escolas, ou ainda, obter oportunidades de acesso à universidade para os estudantes, ou formação continuada para os professores.

$\mathrm{Na}$ fala dos dois professores entrevistados, as palavras "indígenas" e "escola" foram as mais impactantes. A escola é evidenciada como um espaço de poder absoluto, de práticas institucionalizadas, que não dá abertura para outros espaços de aprendizagem e saberes tradicionais, algo conflitante com a tradição cultural indígena. $\mathrm{O}$ indígena, como sujeito representativo, aparece descontextualizado de uma realidade na qual deveria ser o protagonista. A narrativa mostra a existência de professores não indígenas nas escolas indígenas da região sul do Brasil. O aspecto da representatividade indígena reflete a fala sobre a falta de concursos e formação específica de professores para atuarem 
em escolas indígenas; bem como, aparece nos problemas relatados sobre a reprodução de materiais didáticos, que não levam em conta questões linguísticas e culturais das comunidades, devido à elaboração de currículos e projetos políticopedagógicos não diferenciados, ou seja, que não são elaborados em atendimento ao "indígena".

A entrevista com a pesquisadora da universidade trouxe à baila a importância dos projetos de pesquisa que envolvam escolas indígenas e universidades. A palavra destacada na entrevista foi "escola": espaço no qual é possível ocorrer ações e projetos, visando à formação de professores. Um projeto de formação de professores indígenas, fundamentado na parceria entre universidade e comunidade indígena, permite e facilita a reflexão sobre a construção de uma escola diferenciada. $\mathrm{Na}$ visão desta entrevistada, esse tipo de escola mais personalizada considera transformar o currículo atual, a partir da produção e publicação de materiais didáticos na língua materna dos indígenas. Para a pesquisadora, a relação do currículo com o projeto político-pedagógico precisa se voltar para a revitalização de línguas, cultura e tradição das terras indígenas e das etnias nas comunidades indígenas de forma abrangente.

Para os gestores educacionais entrevistados, representantes do MEC, os termos de maior impacto são "indígenas", "professores" e "educação". A palavra "indígenas" se relaciona com os sentidos da ameaça e da mobilização - ameaça no sentido do sujeito que sofre pela insegurança de perder suas terras, a falta do apoio social ao cultivo e à moradia, os problemas de infraestrutura e saúde, e a convivência conturbada com os povos não indígenas; a mobilização, no sentido do sujeito que é atuante, articulado e se mobiliza para garantir que seus direitos adquiridos sejam efetivados.

Seguindo nessa narrativa dos gestores, evidencia-se a valorização dos profissionais que atuam nas escolas indígenas: o professor e o diretor escolar. A palavra "professor" aparece vinculada ao processo de formação a ser ofertado para professores indígenas, ou não, por certo que contemple todos aqueles que atuam em escolas indígenas; devendo esse processo de formação ser mais integrado, e, de modo sistêmico abranger o movimento e as transformações que se espera (re)formular e (re)construir com adoção do I PNEEI. Esse aspecto também condiz com mais concursos públicos para os profissionais da educação indígena e menos contratos temporários, visto que não trazem garantia de trabalho permanente aos professores, nem plano de carreira. Ademais, existe uma relação de significados da palavra "professores" com a capacitação dos diretores escolares. Além da formação, os diretores precisam gerir com responsabilidade social e administrativa as escolas indígenas. Finalmente, o termo "educação" aparece vinculado ao sentido de se ofertar condições adequadas de infraestrutura 
às escolas. Esse aspecto corresponde atender à demanda das comunidades indígenas pelo acesso e a garantia aos prédios escolares, à merenda, ao transporte (nos casos que se aplicam), entre outros.

O Quadro 1 apresenta informações sobre os contextos que configuram as ações referentes aos processos da EEI, pertencentes aos atores envolvidos e mencionados nas narrativas. As categorizações identificadas - desafios, necessidades e prioridades do I PNEEI - tratam sobre aspectos de discussões dos problemas que impactam as decisões políticas no âmbito da educação escolar indígena.

\section{Quadro 1 - Contexto de ações no processo da EEI}

\begin{tabular}{|c|c|c|c|}
\hline $\begin{array}{l}\text { Atores presentes nas } \\
\text { narrativas }\end{array}$ & Quais são seus desafios? & Quais são suas necessidades? & $\begin{array}{l}\text { Quais das metas descritas no } \\
\text { I PNEEl são prioritárias? }\end{array}$ \\
\hline $\begin{array}{l}\text { Comunidades } \\
\text { (Povos indígenas) }\end{array}$ & $\begin{array}{l}\text { Discutir a elaboração do I PNNEI. } \\
\text { Participar ativamente da escola } \\
\text { e compartilhar seus saberes } \\
\text { tradicionais. } \\
\text { Acreditar que o que está sendo } \\
\text { proposto nas audiências será } \\
\text { executado. }\end{array}$ & $\begin{array}{l}\text { Os estudantes possam progredir } \\
\text { nos estudos; e, chegar à } \\
\text { universidade. } \\
\text { Maior representatividade, atuando } \\
\text { na direção e na docência, em } \\
\text { escolas indígenas. } \\
\text { Autonomia e segurança jurídica em } \\
\text { relação à regularização fundiária de } \\
\text { suas terras. }\end{array}$ & $\begin{array}{l}\text { Construção de escolas. } \\
\text { • Formação de professores. } \\
\text { • Regulamentação dos TEEs. } \\
\text { Cumprimento de todas as } \\
\text { metas estipuladas no I PNEEI. }\end{array}$ \\
\hline $\begin{array}{l}\text { Professores } \\
\text { (Professores das } \\
\text { escolas indigenas) }\end{array}$ & $\begin{array}{l}\text { Ampliar diálogos para promover } \\
\text { decisões coletivas junto às } \\
\text { comunidades. }\end{array}$ & $\begin{array}{l}\text { Formação específica para } \\
\text { educadores indigenas. } \\
\text { Plano de carreira. }\end{array}$ & \multirow{2}{*}{$\begin{array}{l}\text { - Formação de professores e } \\
\text { gestores escolares. } \\
\text { - Produção de materiais } \\
\text { didático-pedagógicos, } \\
\text { diferenciados e específicos, em } \\
\text { atendimento à alfabetização na } \\
\text { língua materna dos indígenas. }\end{array}$} \\
\hline $\begin{array}{l}\text { Gestores das escolas } \\
\text { indígenas } \\
\text { (Diretores das escolas; } \\
\text { gestores das secretarias } \\
\text { de educação) }\end{array}$ & $\begin{array}{l}\text { Promover a escolarização indígena } \\
\text { em atendimento às comunidades e } \\
\text { em respeito à legislação vigente. } \\
\text { Adotar princípios de coletividade } \\
\text { junto às comunidades locais. }\end{array}$ & $\begin{array}{l}\text { Compreender os diferentes espaços } \\
\text { de conhecimento, sob a perspectiva } \\
\text { a pedagógica indigena. } \\
\text { Oferta de cursos para os gestores } \\
\text { escolares indígenas. }\end{array}$ & \\
\hline $\begin{array}{l}\text { Pesquisadores } \\
\text { (Pesquisadores das } \\
\text { universidades que } \\
\text { apoiam projetos na EEI) }\end{array}$ & $\begin{array}{l}\text { Construir um currículo diferenciado } \\
\text { para os professores indígenas. }\end{array}$ & $\begin{array}{l}\text { Inserir os saberes indígenas no } \\
\text { currículo tradicional. }\end{array}$ & $\begin{array}{l}\text { Produção de um currículo } \\
\text { diferenciado. }\end{array}$ \\
\hline $\begin{array}{l}\text { Agentes e } \\
\text { formuladores de } \\
\text { políticas públicas } \\
\text { (CNEEl; gestores do } \\
\text { MEC; Gerências de } \\
\text { Ensino Regionais } \\
\text { (GEREDs); CNE) }\end{array}$ & $\begin{array}{l}\text { Elaborar as metas das } \\
\text { conferências. } \\
\text { Envolver diferentes agentes } \\
\text { (privados, públicos e do terceiro } \\
\text { setor) no processo. } \\
\text { Mobilizar estados, municípios e } \\
\text { Distrito Federal para implementar } \\
\text { as ações. } \\
\text { Realizar projetos interministeriais } \\
\text { para melhorar as condições de vida } \\
\text { dos indígenas. }\end{array}$ & $\begin{array}{l}\text { Discutir a elaboração do I PNNEI. } \\
\text { Obter recursos financeiros } \\
\text { necessários para avançar na } \\
\text { execução das metas propostas. } \\
\text { Sensibilizar a sociedade em geral } \\
\text { sobre as especificidades dos } \\
\text { povos indigenas e seus direitos } \\
\text { legalmente instituídos. }\end{array}$ & $\begin{array}{l}\text { Construção de escolas. } \\
\text { Cumprimento de todas as } \\
\text { metas estipuladas no I PNEEI. }\end{array}$ \\
\hline
\end{tabular}

Fonte: Autores, 2020. 


\section{DISCUSSÕES A RESPEITO DE UMA PARTICIPAÇÃO SIGNIFICATIVA POR MEIO DA ESCOLARIZAÇÃO ABERTA}

Primeiramente, é necessário retomar o sentido da sociedade em rede e a sua capacidade de absorver para o contexto social o uso das novas tecnologias. Como visto em Castells (2010), deve-se identificar que já somos pertencentes a essa sociedade, ou seja, não é algo para o futuro, todavia, é preciso considerar no presente a atual sociedade com seus diferentes graus e formas e sua (inter) dependência de países e culturas. Nesse contexto, as comunidades indígenas não podem ser vistas como excluídas da sociedade em rede, portanto, devem ser identificadas como parte das conexões desta sociedade.

Entre as transformações econômicas, sociais e midiáticas que a sociedade vivencia, Castells (2010) informa sobre a necessidade de reconversão total do sistema educativo, incluindo tecnologias, pedagogias, conteúdos e organização da aprendizagem. Então, nesse sentido, não é pela distância geográfica ou pela falta de tecnologia que as comunidades indígenas precisam ficar excluídas dos movimentos inovadores da educação, pois podem ser atores, atuantes deste movimento, no momento em que possuem autonomia para construir seu currículo diferenciado.

$\mathrm{Na}$ educação em rede, pedagogias, metodologias e tecnologias podem ser aplicadas de modo efetivo e direcionadas para o bem comum (GOMEZ, 2015; SOUZA, 2015). Assim, esse conjunto - pedagogia, tecnologia e metodologia orientará os sujeitos a pensar e atuar nas suas próprias redes, nas conexões com as outras redes e na integração de uma rede sistêmica que impacta sobre a educação que se deseja construir.

[...] o homem, a sociedade, o meio ambiente, os sistemas de ideias interagem entre si, por meio de trocas, porque são sistemas abertos. As informações, são, pois os códigos da dinâmica de complexificação de qualquer sistema, sendo que as trocas se dão simultaneamente, intra e intersistemas. Daí que cada sistema da célula ao mundo das ideias -, ao receber novas informações, promove uma reorganização do padrão anterior, que permite a expressão das singularidades e desvios, resguardadas as características universais, porque comuns a todos os objetos e fenômenos do mundo. (MORIN, 2006, p. 27).

Nesse sentido, para Morin, o pensamento complexo tenta religar algo que foi separado e parcializado pelo pensamento disciplinar e compartimentado, passando de uma educação que ensina em separar coisas para uma educação que (re)junta uma informação ao seu contexto e ao conjunto ao qual pertence. Nessa análise, o pensamento complexo contribui para um ensaio que não vislumbra 
apenas a escolarização indígena, todavia, contempla uma escolarização aberta indígena, fundamentadas em uma educação em rede e apoiada pela abordagem RRI.

Desse modo, a participação social possibilita o desenvolvimento de possíveis projetos de escolarização aberta indígena, considerando que esse é um processo que não deve ser feito apenas por um ator social (OKADA; RODRIGUES, 2018). Um projeto de escolarização aberta conta com o apoio da sociedade, visto que é fundamentado em valores baseados na abertura, na ética da participação e na colaboração (AIRES, 2016; PETERS, 2008). Essa é uma prática que se desvincula dos fundamentos do sistema tradicional de ensino, que é fragmentado, como posto por Morin (2006). Como pressuposto apresentado, a escolarização aberta pode ser um fator crítico de sucesso para se inovar na EEI.

Nesse contexto, de acordo com Okada e Rodrigues (2018, p. 51), a escolarização aberta "refere-se às parcerias entre escolas, comunidades locais, famílias e instituições visando conectar as três abordagens de aprendizagem (formal, informal e não formal)." Desse modo, a realização de um projeto de escolarização aberta indígena não resultaria somente no fato da comunidade participar ou não do projeto, a fim de conhecer esse processo. Essa participação implicaria no modo como a comunidade indígena poderia contribuir para "participar ativamente da escola e compartilhar seus saberes tradicionais", que foi um contexto identificado como um desafio neste artigo.

Okada e Rodrigues (2018, p. 50-51) informam quais grupos da sociedade devem estar envolvidos em projetos de escolarização aberta:

1) Agentes de políticas públicas ou "criadores e gestores de políticas públicas" - formadores de opinião, políticos, diretores de centros de pesquisa e representantes de sociedades científicas; líderes de comunidades - atores que devem definir como a pesquisa e a inovação devem ser realizadas, em sua área de influência, dentro das diferentes esferas de atuação;

2) "Comunidades de pesquisa": compostas por acadêmicos, pesquisadores, cientistas inovadores, gerentes de pesquisa, organizações oficiais de assuntos públicos e de comunicação, estando representadas nos sistemas de pesquisa e inovação;

3) "Comunidade de educação": formada por professores, formadores de docentes, coordenadores pedagógicos, desenvolvedores de cursos, estudantes, profissionais de museus de ciências e famílias, que são atores envolvidos com educação, em todos os níveis e modalidades, incluindo as escolas primárias até os estudos de pós-graduação; 
4) Agentes empresariais (ou "Indústria empresarial"): representam os grupos de empreendedores profissionais das grandes, médias e micro empresas, incluindo organizações e instituições transnacionais que também tem interesse na pesquisa;

5) "Sociedade e organização civil": indivíduos e organizações, incluindo as não governamentais, comunidades, profissionais dos meios de comunicação, representantes da sociedade civil, representados pelos cidadãos que ocupam papel essencial para direcionar a pesquisa e a inovação para atender as necessidades da sociedade.

Ademais, no início deste artigo, destacou-se a necessidade de uma metodologia de avaliação de políticas públicas considerarem a forma pela qual as comunidades atingidas pela política devem participar desse processo. Nesse contexto, quaisquer políticas que envolvam as prioridades elencadas pelos entrevistados - como as de construir novas escolas, demarcar e regulamentar terras indígenas, desenvolver um currículo diferenciado, formar e capacitar os profissionais da educação indígena - precisam estar apoiadas em pesquisas científicas.

Nas comunidades indígenas, o desenvolvimento de um projeto de escolarização aberta baseado em RRI possibilitaria esse caminho de participação e fonte científica, no qual os quatro princípios de RRI devem ser considerados:

1) Abertura e transparência: significa comunicar de maneira equilibrada e significativa métodos, resultados, conclusões e implicações para permitir o controle público e o diálogo, criando benefícios e dando visibilidade para o entendimento de pesquisa e inovação (RRI-TOOLS, 2019). Nos projetos de escolarização aberta desenvolvidos com as comunidades indígenas, isso representaria maior envolvimento, consciência e transparência sobre o que se está pesquisando; se existiria um possível risco, de forma a promover a educação de maneira ética e com respeito às tradições e cultura local;

2) Antecipação e reflexividade: relaciona-se com a necessidade de prever impactos e refletir sobre as premissas, valores e propósitos subjacentes para entender melhor como a pesquisa e a inovação molda o futuro, produzindo informações valiosas e aumentando a capacidade de agir de acordo com o que se sabe (RRI-TOOLS, 2019). Essa previsão permite uma participação mais segura do que está por vir, em respeito à integridade das comunidades e em consideração ao compartilhamento e integração de seus saberes no processo;

3) Responsividade e adaptatividade: significa ser capaz de modificar modos de pensamento e comportamento, estruturas organizacionais abrangentes, em resposta a circunstâncias, conhecimentos e perspectivas em mudança, alinhando a ação com as necessidades expressas pelas partes interessadas e 
pelo público (RRI-TOOLS, 2019). Este princípio corresponde à capacidade de resposta e mudança adaptativa que deve acontecer, considerando as necessidades apresentadas nas narrativas, entre as quais estão a compreensão dos diferentes espaços de conhecimento, sob a perspectiva pedagógica indígena e a formação integral do estudante;

4) Diversidade e inclusão: refere-se ao envolvimento, desde cedo, de vários atores e públicos na prática, para deliberar e tomar decisões de pesquisa e desenvolvimento, a fim de gerar conhecimento mais útil e de maior qualidade, fortalecendo aspectos da democracia e ampliando fontes de conhecimento, disciplinas e perspectivas (RRI-TOOLS, 2019). Esse aspecto infere na importância dos representantes (cidadãos e líderes) das comunidades indígenas serem atuantes e terem autonomia, em um processo de deliberação e inclusão, de tal modo que aconteça um processo de inovação social e associação às demais redes.

Por fim, é relevante destacar que se busca, sob a perspectiva do pensamento complexo, uma incorporação de elementos exteriores para serem somados, em busca do alcance de objetivos em que os elementos escolhidos dialogam com o jeito de ser das comunidades indígenas (PIMENTEL, 2012). Isso significa que a apresentação dos princípios de RRI, quando incorporados a um projeto de escolarização aberta, como um elemento a ser somado à EEI, necessita fazer sentido para as comunidades participantes do processo educativo, carecendo da apresentação de interesse das mesmas pelo projeto - que não pode ser algo estranho ou imposto, ou seja, com sentido de pertencimento - para que ocorra o valor emancipatório e democrático da educação em rede.

\section{CONSIDERAÇÕES FINAIS}

No campo interdisciplinar, do pensamento complexo, este estudo abre pressupostos para investigação de projetos de escolarização aberta indígena, fundamentados na abordagem RRI. O artigo se apoia na reflexão de se ter uma participação mais significativa das comunidades indígenas nos processos educativos, referentes à EEI.

Para sustentar essa proposta, emprega-se como metodologia à pesquisa exploratória de abordagem qualitativa, em que se adotam como métodos: o levantamento bibliográfico, explorando o contexto da pesquisa e inovação responsáveis e educação em rede; o levantamento documental, com base na resolução CNE/CEB no 5 de 2012 e no documento norteador para elaboração do I PNEEI; observação em campo, na sexta audiência pública, ocorrida em 
Chapecó-SC para elaboração do I PNEEI; e, por fim, a entrevista narrativa realizada com atores envolvidos para a construção do I PNEEI, para compressão significativa dos processos que dizem respeito à EEI.

Como análise e resultados apresentados, a partir das narrativas dos sujeitos entrevistados, revelam-se termos para significar a ação dos atores envolvidos, considerando os desafios, as necessidades e as prioridades quanto às metas apresentadas para a elaboração do I PNEEI (Quadro 2). A construção de escolas nas comunidades indígenas, a regulamentação dos TEEs; a formação de professores para atuar nessas escolas e a produção de materiais didáticopedagógicos, diferenciados e específicos, para alfabetização na língua materna dos indígenas mais uma vez reforçam, e não minimizam o desejo desses atores no alcance de toda a execução do plano proposto.

Nas discussões, apresenta-se como resultado das reflexões o sentido mais significativo da participação das comunidades indígenas nos processos da EEI. As comunidades indígenas pertencem à sociedade em rede (CASTELLS, 2010) e não devem ser excluídas por ela. Desse modo, essas comunidades podem ser integradas e se integrarem, caso seja de seu interesse, em processos educativos inovadores. A visão da educação em rede (GOMEZ, 2015; SOUZA, 2015) proporciona que pedagogias, tecnologias e metodologias sejam usadas a favor dos sujeitos nas redes. Nesse contexto, contempla-se uma escolarização aberta indígena, fundamentada na educação em rede e apoiada pela abordagem RRI para resolução de problemas sociocientíficos (OKADA; SHERBORNE, 2018), valorizando os saberes das comunidades indígenas também dentro do espaço formal da escola.

A RRI reforça o contexto da participação mais significativa de diferentes atores nos projetos de escolarização aberta (OKADA; RODRIGUES, 2018). Em uma escolarização aberta indígena, baseada em RRI, devem ser considerados os seguintes princípios: abertura e transparência; antecipação e reflexividade; responsividade e adaptatividade; diversidade e inclusão.

Enfim, o estudo delimita-se na apresentação de pressupostos teóricos, fundamentado em um recorte específico de investigação. Desse modo, favorece que outras pesquisas avancem o contexto aqui apresentado, trazendo a campo para o debate os entendimentos e contestações que se propõe. 


\section{REFERÊNCIAS}

ABBONIZIO, A.; GHANEM, E. Educação escolar indígena e projetos comunitários de futuro. Educação e Pesquisa, v. 42, n. 4, p. 887-901, 2016.

AGUILAR, M. Aprendizaje y tecnologías de información y comunicación: hacia nuevos escenarios educativos. RLCSNJ, v. 10, n. 2, 2012.

AIRES, L. e-Learning, educação online e educação aberta: contributos para uma reflexão teórica. RIED. Revista Iberoamericana de Educación a Distancia, v. 19, n. 1, 2016, p. 253-269.

BRASIL. Ministério da Educação. Diretrizes Curriculares Nacionais para a Educação Escolar Indígena. Parecer homologado CNE/CEB no 13/2012, de maio de 2012. Diário Oficial da União, Seção 1, p. 18, 15 jun. 2012.

CAMARGO JUNIOR, K. R.; MOURA, E. G. A crise no financiamento da pesquisa e pós-graduação no Brasil. Cad. Saúde Pública [online]. 2017, vol.33, n.4. Disponível em: https://www.scielo.br/scielo.php?script=sci_ arttext\&pid=S0102-311X2017000400101\&lng=pt\&tlng=pt. Acesso em: 20 de junho de 2020 .

CASTELLS, M. A sociedade em rede. São Paulo: Paz e Terra, 2010. v. 1.

CELlARD, A. A análise documental. In: POUPART, J. et al A pesquisa qualitativa: enfoques epistemológicos e metodológicos. Petrópolis, Vozes, v. 295, p. 2010-2013, 2008.

CRESWELL, J. W. Pesquisa qualitativa e desenho da pesquisa: escolhendo entre cinco abordagens, v. 2, 2010.

EUROPEAN COMMISSION. Horizon 2020: work programme 2014-2015science with and for society. European Commission Decision C. 2015.

FISCHER, E. Condições necessárias para a inovação responsável. Journal of Responsible Innovation, 7:2, 145-148, 2020. Disponível em: https://www. tandfonline.com/loi/tjri20. Acesso em: 15 de junho de 2020. 
GIL, A. C. Métodos e técnicas de pesquisa social. 6. ed. São Paulo: Atlas, 2008.

GOMEZ, M. V. Educação em rede: uma visão emancipadora. São Paulo: Cortez, 2004.

GOMEZ, M. V. Pedagogia da virtualidade: redes, cultura digital e educação. São Paulo: Edições Loyola, 2015.

INSTITUTO DE PESQUISA ECONÔMICA APLICADA (IPEA). Avaliação de políticas públicas: guia prático de análise ex ante. Brasília, DF: Casa Civil da Presidência da República, 2018. v. 1. p. 192.

INSTITUTO NACIONAL DE ESTUDOS E PESQUISAS EDUCACIONAIS ANÍSIO TEIXEIRA (INEP). Censo Escolar da Educação Básica 2018: notas estatísticas. Brasília, DF, 2019.

MINISTÉRIO DA EDUCAÇÃO (MEC). MEC promove audiência pública para plano de educação escolar indígena. Brasília, DF, 20 de maio de 2019. Disponível em: <http://portal.mec.gov.br/ultimas-noticias/2061084311476/76151-mec-promove-audiencia-publica-para-plano-de-educacaoescolar-indigena> . Acesso em: 7 set. 2019.

MORIN, E. Complexidade e ética da solidariedade. In: CASTRO, G. et al. Ensaios de complexidade. Porto Alegre: Editora Sulina, 2006.

MURA, F. Do desenvolvimento comunitário à mobilização política: o projeto Kaiowa-Ñandeva como experiência antropológica. Mana, Rio de Janeiro, v. 8, n. 2, p. 212-216, 2002.

MUYLAERT, C. J. et al. Entrevistas narrativas: um importante recurso em pesquisa qualitativa. Revista da Escola de Enfermagem da USP, v. 48, n. SPE2, p. 184189, 2014.

MINAYO, M. C. S. Pesquisa social: teoria, método e criatividade. Petrópolis: Vozes, 1994. 
NUNES, L. L. S. et al Educação em rede: tendências tecnológicas e pedagógicas na sociedade em rede. EmRede - Revista de Educação a Distância, v. 3, n. 2, p. 197-212, 2017.

OKADA, A. Responsible research and innovation in science education report.Milton Keynes: The Open University - UK, 2016.

OKADA, A.; RODRIGUES, E. A educação aberta com ciência aberta e escolarização aberta para pesquisa e inovação responsáveis. In: TEIXEIRA, C.; SOUZA, M. V. Educação Fora da Caixa: tendências internacionais e perspectivas sobre a inovação na educação. São Paulo: Blucher, 2018. v. 4.

OKADA, A.; SHERBORNE, T. Equipping the next generation for responsible research and innovation with open educational resources, open courses, open communities and open schooling: an impact case study in Brazil. Journal of Interactive Media in Education, v. 1, n. 18, p. 1-15, 2018.

OWEN, Richard. Responsible Research and Innovation: options for research and innovation policy in the EU. European Research and Innovation Area Board (ERIAB), Foreword Visions on the European Research Area (VERA), 2014.

OWEN, R.; PANSERA, M. Responsible innovation and responsible research and innovation. In: HANDBOOK on science and public policy. Edward Elgar Publishing, 2019.

PETERS, M. A. The history and emergent paradigm of open education. In: OPEN education and education for openness. Brill Sense, 2008. p. 1-15.

RRI-TOOLS. What is RRI?. Disponível em: https://www.rri-tools.eu/pt/ homepage. Acesso em: 19 out. 2019.

ROSA, L. Q. et al. Polo EaD como mídia do conhecimento na indústria 4.0. In: CONGRESSO INTERNACIONAL DA ABED DE EDUCAÇÃO A DISTÂNCIA. 2018, Florianópolis. Anais [...]. Florianópolis: ABED, 2018.

SENADO FEDERAL. Senado Notícias. Site oficial. Brasília, DF, 22 jun. 2020. Disponível em: https://www12.senado.leg.br/noticias/materias/2020/06/22/ senadores-manifestam-solidariedade-pelos-mais-de-50-mil-mortos-por-covid-19. Acesso em: 22 jun. 2020. 
SHIRKY, Clay. Here comes everybody: The power of organizing without organizations. Penguin, 2008.

SOUZA, M. V. Mídias Digitais, Globalização, Redes e Cidadania no Brasil. In: SOUZA, M. V.; GIGLIO, K. (Eds.). Mídias digitais, redes sociais e educação em rede: experiências na pesquisa e extensão universitária. São Paulo: Blucher, 2015.

VON SCHOMBERG, Rene. A vision of responsible research and innovation. In: RESPONSIBLE innovation: managing the responsible emergence of science and innovation in society. 2013. p. 51-74.

\section{Luziana Quadros da Rosa}

Doutoranda em Mídia do Conhecimento, no Programa de Pós-Graduação em Engenharia e Gestão do Conhecimento, pela Universidade Federal de Santa Catarina Florianópolis (UFSC). Mestra em Tecnologias da Informação e Comunicação (UFSC).E-mail: cpead.bpi.luziana@gmail.com

\section{Marcio Vieira de Souza}

Doutor em Engenharia de Produção (UFSC). Professor Permanente no Programa de Pós-Graduação em Engenharia e Gestão do Conhecimento, da Universidade Federal de Santa Catarina (UFSC), Florianópolis - SC, Brasil. Líder do Grupo de Pesquisa Mídia e Conhecimento,CNPq.E-mail: marciovieiradesouza@gmail. com

\section{Alexandra Okada}

Pesquisadora Sênior da Academia Superior de Educação (UK). Pesquisadora e Professora Honorária, $\mathrm{PhD} \& \mathrm{MSc}$ Educação, BSc Ciências da Computação, Postdoc Educação Aberta. Líder da Comunidade Colearn e RRIData.com. E-mail: ale.okada@open.ac.uk 